\title{
GOVERNANDO POR MEIO DA INSENSIBILIDADE: A Segurança Pública e Gestão Biopolítica dos Corpos - A Administração da Morte nas Prisões
}

\author{
http://dx.doi.org/10.21527/2176-6622.2021.56.10350
}

Recebido em: 12/3/2020

Modificações solicitadas em: 18/11/2020

Aceito em: 4/1/2021

Jackson Silva Leal

Autor correspondente. Universidade do Extremo-Sul Catarinense (PPGD-Unesc). Av. Universitária, $1105-$ Bairro Universitário. Criciúma/SC, Brasil. CEP: 88806-000. http://lattes.cnpq.br/8756216995959645. https://orcid.org/0000-0002-0779-1103. jacksonsilvaleal@gmail.com

Alex da Rosa

Universidade do Extremo-Sul Catarinense (PPGD-Unesc). Criciúma/SC, Brasil.

\section{RESUMO}

O presente trabalho aborda o fenômeno da mortalidade prisional-policial, como uma marca do sistema penal brasileiro que se apresenta de maneira permanente, inerente a seu próprio funcionamento. Assim, visa-se a contribuir com a análise acerca do permanente massacre em que tem se constituído a segurança pública brasileira, esse programa de fundamental importância política eleitoral - assim como mercadológica - e que permita trabalhar com a ideia de governando por meio do crime, já apontado por Jonathan Simon, e que aqui se aborda em uma face ainda mais grosseira, que é governando por intermédio da insensibilidade e da administração de massacres, sejam eles em praça pública, ou dentro da presídios e penitenciárias como aparelhos (últimos) da segurança pública. Metodologicamente este trabalho se desenvolve como um esforço teórico analítico, que entre uma infinidade de abordagens possíveis, realiza-se uma análise foucaultiana-agambeniana, teórica, crítica e reflexiva, portanto que não explicam a totalidade do problema, mas que agregam elementos para pensar a construção de subjetividades bárbaras que estão debaixo e detrás dessa realidade sangrenta e insensível ao sofrimento. $O$ objetivo é apontar elementos e chaves de análise diante da realidade de expansão do segregacionismo que a prisão representa o ápice, e como se tem constituído uma organização e relações sociais pautadas desde uma subjetividade destrutiva e aniquiladora do outro que é a morte do "eu" na condição de sujeito (ser social). A conclusão encaminha-se no sentido de que a política criminal brasileira apresenta-se como uma verdadeira política de morte, dentro e fora do cárcere, uma política de gestão de coletivos indesejáveis, a partir da lógica do deixar morrer.

Palavras-chave: Encarceramento em massa; massacres prisionais; segurança pública; governando através do crime; gestão biopolítica.

\section{GOVERNING THROUGH INSENSIBILITY: PUBLIC SECURITY AND BIOPOLITIC BODY MANAGEMENT - THE ADMINISTRATION OF DEATH IN PRISONS}

\section{ABSTRACT}

The present work addresses the phenomenon of prison-police mortality, as a mark of the Brazilian penal system that presents itself permanently, inherent to its own functioning. Thus, the aim is to contribute to the analysis of the permanent massacre that Brazilian public security has been constituted, this program of fundamental electoral political importance - as well as marketing - and that allows working with the idea of governing through crime, already pointed out by Jonathan Simon, and which is approached here in an even cruder face, which is governing through insensitivity and the administration of massacres, whether in public square, or inside prisons and penitentiary as (last) public security devices. Methodologically, this work is developed as a theoretical analytical effort, which among a multitude of possible approaches, carries out a Foucault-Agambennian analysis, which is theoretical, critical and reflective, therefore; that do not explain the totality of the problem but that add elements to think about the construction of barbaric subjectivities that are below and behind this bloody and insensitive reality to suffering. The objective is to provide elements and keys of analysis in face of the reality of expansion of segregationism that the prison represents the summit, and how an organization and social relations based on a destructive and annihilating subjectivity of the other, which is the death of the ' $I$ ', have been constituted as a subject (social being). The conclusion goes in the direction that the Brazilian criminal policy, presents itself as a true policy of death, inside and outside the prison, a policy of management of undesirable collectives, from the logic of letting die.

Keywords: Mass incarceration; prison massacres; public security; ruling through crime; biopolitical management. 
GOVERNANDO POR MEIO DA INSENSIBILIDADE:

A SEGURANÇA PÚBLICA E GESTÃO BIOPOLÍTICA DOS CORPOS - A ADMINISTRAÇÃO DA MORTE NAS PRISÕES

Jackson Silva Leal - Alex da Rosa

\section{INTRODUÇÃO}

No dia 29 de julho de 2019 ocorreu no Centro de Recuperação Regional de Altamira, no Pará, uma rebelião que gerou 57 mortos. Entre os mortos, 16 foram decapitados e 41 asfixiados pelo incêncio, durante o conflito que durou menos de cinco horas e originou-se da disputa entre as facções "Comando Vermelho" e "Comando Classe A" pelo controle do tráfico na região $(G 1,2019)$.

Não é inédita a violência nas disputas entre facções, tampouco o massacre/extermínio de grupos em determinados locais. No histórico brasileiro de execuções e mortes em presídios, Altamira se destaca por ter o segundo maior número de mortes, ficando atrás do massacre do Carandirú, em 1992, quando 111 detentos foram assassinados pela Política Militar de São Paulo na ação que visou a retomar o controle do complexo após a rebelião $(\mathrm{G} 1,2019)$.

O objetivo do presente trabalho não é trazer um histórico sobre os massacres no Brasil, tampouco esclarecer especificamente as características do caso de Altamira - embora significativas - mas sim pensar a condições de inércia sobre as quais os massacres têm se apresentado em nossa sociedade, articulados pelos aspectos (a) biopolítico e também (b) midiático, itens que serão objeto de análise dos itens 3 e 4 .

A articulação dos dois dispositivos supramencionados dar-se-á pela complexa categoria de (c) governo (FOUCAULT, 2014), explorando a dimensão subjetiva de tal técnica que não só permite, mas torna possível e provável o desenrolar dessa situação. A arte, ou técnica de governar as subjetividades, possui imbricações e caminhos que serão explorados principalmente nas contribuições de Jonathan Simon em "Governing Through Crime" (2007) e de Nils Christie na obra "Indústria do Controle do Crime" (1998).

Como reflexão provisória e no intento de produzir novos caminhos para compreender o presente, o massacre de Altamira será compreendido como parte de um programa de governo, que, juridicamente, permanece na legalidade, mas que obtém sua legitimação pelo poder midiático - na telemática (FLUSSER, 2007) - e se sustenta principalmente pela produção de inércia no corpo social.

O que queremos propor como problema é: Como o massacre é possível? Além disso, como é tolerado (ou aceito)? Como é normalizado? Quais são as disjunções necessárias no corpo social para a produção de tal inércia? Quais são as produções de subjetividades necessárias para que um massacre faça parte de um programa muito bem aceito e apoiado pela população? Em síntese, essas são as questões que este trabalho visa a agregar elementos para buscar compreender.

Para isso pretendemos fazer alguns apontamentos. O mais fácil é o jurídico. No Direito, ou melhor, nas fundamentações filosóficas do poder de punir, situa-se o ponto entre a legalidade e a legitimação; uma relação fundamentalmente de intersubjetividade, de validade, de anuência, de concordância. Não em nível do pacto social formal, mas de legitimidade real/concreta entre sujeitos, ou seja, construção de uma certa "moral", e evidentemente seu uso político.

Justamente por isso não podíamos desprezar a comunicação, que se apresenta como ponto mais difícil. A importância da comunicação fica mais evidente quando destacamos que se trata da comunicação de subjetividades, das relações que estabelecemos uns com os outros. A mídia, não só sua estrutura massificada de distribuição/difusão de informação, mas principalmente seu caráter imagético e informativo em telas virtuais - o que Flusser chama de Telemática - contribui significativamente para a "formação" das subjetividades.

Tudo isso que expusemos até então articularemos sobre a forma de governo, no sentido que lhe atribuiu Michel Foucault, principalmente em seus estudos da década de 80 . Com as condições estabelecidas, podemos finalmente observar nosso objeto central: a tolerância ao massacre de Altamira, ou melhor, o massacre como programa.

A partir da criminologia, concluímos a relação circular entre o crime e o governo, o que Simon chama de "Governando Através do Crime" (2007). Aliando-se a Simon, dizer como Mathiesen que todo crime é político já nos ajuda em grande parte a compreender o que se busca: o "crime" na condição de ente politicamente construído faz parte de um programa de controle social, em que os massacres estão muito bem inseridos e que funcionam, ambos, como forma de governar a população (função biopolítica), mantendo-se por isso no governo (função subjetiva). 


\section{BIOPOLÍTICA E SEGURANÇA PÚBLICA: FAZER VIVER, DEIXAR MORRER}

Tema já repisado, faremos algumas considerações preliminares e uma síntese do conceito com o fim apenas de expor essa dimensão jurídica sobre a qual decorrem os acontecimentos narrados, assim como estabelecer diferenciações importantes para chegarmos enfim no conceito de governo.

Cumpre destacar um eminente problema que é a utilização do estado de exceção de Agamben, e em geral sua interpretação sobre a biopolítica diante de uma matriz teórica foucaultiana. É complexo por que uma leitura desavisada poderia simplificar as coisas, estabelecer conexões que embora convenientes não correspondem à ordem das interpretações ou estão prejudicas em sua construção.

Dois caminhos possíveis servem de referência: "Perspectivas da Soberania em Carl Schimitt, Giorgio Agamben e Michel Foucault", da autora Flávia D'Urso (2016) e também "Agir em Tempos Sombrios", de Zeynep Gambetti (2019), a segunda autora tida como crítica de Agamben.

Estamos falando inicialmente da biopolítica para demonstrar a evolução pelo dispositivo de segurança e a técnica de governo. Para isso, precisaremos expor alguns elementos do pensamento agambeniano para nos distanciarmos desse caminho. ${ }^{1}$

Primeiramente, a interpretação de Agamben acerca da biopolítica tem como chave a figura do Homo Sacer, o indivíduo incluído pela exclusão, insacrificável, porém matável. (2007, p. 79-95).

A figura do Homo Sacer surge numa relação jurídica, ou seja, é comportada no Estado de exceção, que, segundo o autor, seria caracterizado principalmente pela assunção e concentração dos poderes políticos na figura do chefe do poder Executivo com fins de eliminação (incluir pela exclusão) de segmentos da população - enquanto o poder Legislativo funcionaria simbolicamente ao legitimar os decretos-lei do executivo (AGAMBEN, 2003).

Agamben demonstra como pode a democracia comportar, ou melhor, funcionar a partir desse imbróglio, desse estágio indiscernível - ou seja, Estado de Exceção ${ }^{2}$ de legalidade ou ilegalidade, em que os indivíduos podem ser mortos sem implicação de crime como conduta punível definida como crime (2003).

Nessa linha interessantes contribuições já foram feitas, dispensando, inclusive, outras incursões com a mesma abordagem teórica. A exemplo, a obra de Orlando Zaccone aborda minuciosamente o Estado de Exceção e o extermínio da população a partir da ação policial e seus resíduos deixados nos "autos de resistência," rapidamente organizados e legitimados dentro da ordem jurídica (ZACCONE, 2015).

Quando, no entanto, falamos em governo através do crime, não é a isso que estamos nos referindo. Compreender as diferenças dos trabalhos entre Agamben e Foucault nos permitirá desembocar nas técnicas de governo e na noção de subjetivação, elementos fundamentais para visualização do diagnóstico aqui pretendido.

Giorgio Agamben define a sua pesquisa como "precisamente este oculto ponto de intersecção entre o modelo jurídico-institucional e o modelo biopolítico do poder" (2007, p. 14), afirmando que a "produção de um corpo biopolítico seja a contribuição original do poder soberano".

Para ele a biopolítica seria, nesse sentido, pelo menos tão antiga quanto a soberania" (2007, p. 14). Observa-se que o ponto central do autor é reinscrever a soberania nas relações de poder, o que dá ao elemento uma centralidade diversa dos caminhos foucaultianos.

Já o conceito de biopolítica em Foucault tem sua definição mais categórica, por assim se dizer, em 1976, no último capítulo da História da Sexualidade I. Para ele existe uma inversão do poder soberano para o bio-

\footnotetext{
${ }_{1}$ Zeynep Gambetti é base das críticas e distanciamentos presentes neste trabalho, sinteticamente exposto pela autora: "A base metafísica de Homo Sacer é um retrocesso no que tange à compreensão da biopolítica, particularmente na moderna, de modo a ser capaz de contextualizar adequadamente a transformação da fronteira entre a vida e a morte" (2019, p. 28).

A interpretação do autor leva em conta os trabalhos anteriores de Schimitt, Arendt e Benjamin, estabelecendo profundo diálogo.

3 Autos de resistência, como aponta Orlando Zaccone no livro resultado de sua tese de Doutorado, intitulado "Indignos de Vida: a forma jurídica da política de extermínio de inimigos na cidade do Rio de Janeiro"(2015), é a forma jurídica dada ao ato de matar em serviço pelas agências policiais, o meio administrativo prévio em que se verifica a existência ou não de conduta e se ela se adéqua ou não à definição de homicídio. Um procedimento administrativo interno prévio a eventual persecução penal.
} 
poder, que é explicada a partir do sintagma "fazer morrer, deixar viver" e posteriormente "fazer viver, deixar morrer". O primeiro reflete diretamente o poder do soberano sobre a vida do indivíduo, sendo pelo poder de enviá-lo à guerra (ainda que) tendo a morte no horizonte, ou até mesmo matá-lo a título de castigo, modalidade comum das punições medievas (FOUCAULT, 2006, p. 148).

Já o poder biopolítico, o novo poder político do século 19, perpassa o primeiro poder (o soberano), o penetra, modifica, transforma numa inversão: não mais o direito direto sobre a morte, mas sim um controle rigoroso sobre a vida, sobre o bíos, regulando a própria noção de vida e trazendo uma nova relação com a morte.

Do que se trata essa nova tecnologia do poder, nessa biopolítica, nesse biopoder que está se instalando? Eu Ihes dizia em duas palavras agora há pouco: trata-se de um conjunto de processos como a proporção dos nascimentos e dos óbitos, taxas de reprodução, a fecundidade de uma população e etc. São esses processos de natalidade, de mortalidade, de longevidade que, justamente na segunda metade do século XVIII, juntamente com uma porção de problemas econômicos e políticos (os quais não retomo agora), constituíram, acho eu, os primeiros objetos de saber e os primeiros alvos de controle dessa biopolítica. É nesse momento, em todo caso, que se lança mão da medição estatística desses fenômenos mais ou menos espontâneos, mais ou menos combinados(...). Trata-se também do problema da morbidade, não mais simplesmente, como justamente fora o caso até então, no nível daquelas famosas epidemias cujo perigo havia atormentado tanto o poder político desde as profundezas da Idade Média (...) não mais a morte que se abate brutalmente sobre a vida - é a epidemia - mas como a morte permanente, que se introduz sorrateiramente na vida, a corrói perpetuamente, a diminui e a enfraquece (FOUCAULT, 2008, p. 204-205).

No cenário biopolítico a morte não é descartada, é, ao contrário, reorganizada em termos de estratégia e modula o "deixar morrer". Nesse sentido, em termos rigorosos, o biopoder enseja ainda guerras e massacres (FOUCAULT, 2006, p. 149-151), mas também faz pensar a relação direta do governo, mais precisamente do Estado, sobre a vida da população, a partir de políticas públicas de saúde de censos, de controles (uma dinâmica de esquadrinhamento dos corpos e comportamentos e sua vigilância e controles).

Observa-se então a significativa diferença: a opção de Foucault em se "libertar do privilégio teórico da soberania" (2006, p. 80), em pensar a noção de poder por outros caminhos que não privilegiassem modelos estatais, é além de, a característica marcada do autor, um ponto de bifurcação entre a perspectiva foucaultiana e agambeniana.

Em comparação com Foucault, que expressamente quis afastar-se de modelos jurídicos de poder e retirar de suas análises o privilégio teórico da soberania, Agamben precisamente realiza o contrário em seus estudos, tomando como central a concepção de soberania a partir dos conceitos desenvolvidos por Carl Schimitt (D'URSO, 2016, p. 236). ${ }^{4}$

O que significa dizer é que, para Foucault, a biopolítica será característica corolária do dispositivo de "segurança", elementos constituintes de uma "arte" de governo, enquanto para Agambem a biopolítica constituiria um paradigma da soberania com seu exemplo paradigmático do campo de extermínio e Estado de Exceção.

Avançando no sentido foucaultiano da biopolítica - que é elemento visceral das técnicas de governo - em 1978, Foucault (2008), na obra "Segurança, Território e População", a problemática do governo dos homens é proposta num duplo sentido: o conceito de população em detrimento do povo e o governo perante a soberania.

Não obstante a nova relação biopolítica entre governo e população, o autor trabalha seus estudos naquilo que denomina arte de governar, certas técnicas de governo que se aplicariam também à população, mas operariam fundamentalmente no nível do indivíduo, no nível da subjetividade. ${ }^{5}$

\footnotetext{
4 Os apontamentos de Flávia são precisos: "Talvez a dificuldade do Homo Sacer I não seja o que o separa de Foucault, isto é, seu conceber da história da soberania como tendo sido uma "Biopolítica" desde o início. Em vez disso, árdua talvez seja a problematização desse âmbito biopolítico e suas aporias como indissoluvelmente ligadas aos problemas linguísticos e ontológicos" (2016, p. 140). É interessante inclusive ler tal afirmação observando os caminhos que Agamben toma mais ao final de sua obra, principalmente no "Uso dos Corpos" (2017), último volume da série Homo Sacer, que tem grande parte dedica a uma análise ontológica do problema".

5 Como sinaliza Clésio Lemos, tal mudança é assinalada pela própria terminologia utilizada. A mudança do conjunto saber-poder, largamente utilizado durante a década de 70, vem a ser preterido pelo conjunto verdade-governo, numa saída aos problemas e limites que a primeira ferramenta de análise continha (LEMOS, 2018; FOUCAULT, 2014, p. 8-12).
} 
GOVERNANDO POR MEIO DA INSENSIBILIDADE:

A SEGURANÇA PÚBLICA E GESTÃO BIOPOLÍTICA DOS CORPOS - A ADMINISTRAÇÃO DA MORTE NAS PRISÕES

Jackson Silva Leal - Alex da Rosa

A biopolítica seria uma inflexão, sem exclusão de outras técnicas de controle já existentes, mas com modulações fundamentais. Exemplificando, em um primeiro momento, o poder punitivo se articulava na simples norma "não matarás", cujo descumprimento acarretava enforcamento, punição física ou multa.

Já no segundo, ainda sobre a proibição do "não matarás", as punições envolvidas seriam de outra ordem, um esquadrinhamento, prisão em celas, uma vigilância sobre possíveis novos crimes, aí também imbricada a prisão às medidas de correção, moralização, trabalho dos agentes penitenciários, em linhas gerais, o modelo disciplinar (FOUCAULT, 2008, p. 6-10).

O terceiro modelo, ou melhor, modulação sobre a matriz anterior, mantém-se as mesmas proibições, mesma lógica de punição e prisão, acrescentando a isto tudo o novo questionamento, como a taxa de criminalidade, índices sobre tipos penais, estatísticas sobre quantidades de furtos ou outro tipo em cidade $X$ ou $Y$, ao passo que também questiona-se acerca do custo de determinadas ações repressivas (FOUCAULT, 2008, p. 7), em uma dinâmica de constituição de uma economia política da violência (ou da modulação biopolítica das sociedades avançadas).

Em linhas gerais, esse aspecto constitui a dimensão da "segurança" na sociedade, certa preocupação com bens, com estoque, a propriedade privada, será todo o mecanismo da segurança e sua instrumentalização pela disciplina que desenvolverá o aspecto geral de controle, monitoramento, preocupação; não mais com a guerra externa, mas sim com a guerra interna, ensejando inclusive a criação de inimigos internos que reativam constantemente o dispositivo de segurança.

Alargando tal reflexão, essa prática estendeu-se também a outras áreas do governo, passando a ser uma nova forma de poder, preocupado com a vida da população, qual a taxa de mortalidade por faixa etária, qual expectativa de vida, que lesões ou riscos está sujeita a população.

Explorando novamente as mutações no poder punitivo, principalmente da disciplina ao biopoder, Foucault remonta o clássico exemplo da lepra - já estudado desde a História da Loucura - como modelo primário da exclusão e isolamento dos leprosos da sociedade, que embora tivessem certa ritualística, principalmente religiosa, consistiam basicamente num sistema de exclusão (FOUCAULT, 2008, p. 13).

Diferentemente da lepra, a peste mostra outro tipo de controle, marcado pela vigilância e investigação, regulamentação de atividades, lugares a ir, lugares proibidos, obrigação de receber a visita de inspetores, em síntese, o poder disciplinar. A inflexão que conduz a biopolítica é representada pelo modelo da varíola. Não cabe mais apenas controlar espaços e organizar comportamentos, é preciso calcular quantos são infectados, qual extensão da epidemia e como o corpo médico trabalhará sobre isso (FOUCAULT, 2008, p. 14).

Um outro exemplo que caracterizaria bem essa dimensão de controle sobre a vida a partir de práticas estatais sobre o regime geral biológico da população é a "revolta da vacina" ocorrida em 1904 no Rio de Janeiro/RJ, após imposição por parte do governo federal da vacinação obrigatória. Nessa situação, agregam-se elementos: estratégia geral de governo que visa a um controle populacional (biopolítico) e utilização de mecanismos de repressão, tipicamente disciplinares.

Esse tipo de poder, fundamentalmente diferente do soberano, é uma inflexão do modelo disciplinar, uma certa aliança entre o esquema de segurança vigente nas sociedades e um novo tipo de controle que transcende a manipulação das condições gerais da população, essencialmente sua vida, duração, condições em que vive. Verifica-se que originalmente o binômio Soberano/Povo, como paradigma de poder, perde força perante o Governo/População.

Nesse sentido, tudo levaria a crer em uma verdadeira endemia criminal, tendo em vista as estatísticas sobretudo de encarceramento, como se pode verificar na sintetização dos dados encontrados em Por Trás das Grades (2018) de Victor Martins Pimenta, que demonstra o quanto se prende no Brasil recente, a que se tem definido como "Era do Superencarceramento". O autor mostra que o Brasil passa de uma população carcerária de 361 mil presos (em 2005) para 726 mil (em 2016), e sequer esses dados dão conta da realidade, pois informações mais recentes apontam a ultrapassagem dos 800 mil presos ao final de 2019 (BRASIL, 2018).

Esse quadro poderia, aos desavisados, levar a crer em um crescimento vertiginoso da violência em um período de 15 anos, que justificaria tal escalada nos índices de encarceramento. Como aponta Salo de CarvaIho, entretanto, em um livro intitulado O papel do Atores do Sistema Penal na Era do Punitivismo: o exemplo 
GOVERNANDO POR MEIO DA INSENSIBILIDADE:

A SEGURANÇA PÚBLICA E GESTÃO BIOPOLÍTICA DOS CORPOS - A ADMINISTRAÇÃO DA MORTE NAS PRISÕES

Jackson Silva Leal - Alex da Rosa

privilegiado da aplicação da pena (2010), que procura dar conta da mentalidade punitiva no sistema de Justiça brasileira, e que entre tantas coisas que apresenta, a que mais importa para o trabalho nesse momento é de que a taxa de crimes violentos apresenta-se absolutamente estável desde o ano 2000 (2010, p. 46).

Na mesma linha da problemática do encarceramento, verifica-se no Anuário Brasileiro de Segurança Pública 2019 que as mortes por policiais militares nos anos de 2017 e 2018 chegaram a 3.579 (2017) e 3.446 (2018), em serviço e fora dele (em números absolutos), quando o mesmo Anuário mostra uma trajetória de diminuição dos crimes graves, como homicídios e latrocínios, exemplificativamente.

Nesta intersecção é que se situa o presente trabalho, onde e como o professor Luiz Antônio Bogo Chies et al (2018) vão denominar em seu artigo prisões [e policiais] que matam, e mortes que pouco importam, em que apresentam os dados acerca das mortes sob custódia prisional no Brasil, quando se constata 769 mortes em 2013, 798 em 2014 e 954 em 2015. Ou seja, Altamira não se constitui em um fato isolado e excepcional, e tampouco Carandiru foi o primeiro massacre e o mais numeroso, pois a chacina prisional apresenta-se perene, constante e sobretudo, silenciosa.

Por ora permite-se fazer a relação de que, se os índices de criminalidade, sobretudo a violenta, não estão aumentando, ao mesmo passo verifica-se incessantemente um aumento vertiginoso do encarceramento e da violência letal da polícia e ampliação das mortes de pessoas custodiadas. O que se tem em mãos é justamente uma dinâmica de governo por meio do crime, do controle (letal) dos corpos - controle biopolítico do fazer viver, deixar morrer.

Como apontou há muito Nils Christie (1993), de maneira visionária, exatamente que as variáveis encarceramento e criminalidade tinham pouco a ver uma com a outra. E que a taxa de encarceramento tem muito mais relação com as escolhas políticas, ou seja, o crime é político, e as taxas de encarceramento e sofrimento prisional apresentam-se como uma determinação política, de quanto crime e sofrimento prisional queremos ter, conforme termina o autor em outra obra: Quando o bastante é o bastante? (CHRISTIE, 1993).

\section{NARRATIVAS, DISCURSOS E SUBJETIVIDADE: A CONSTRUÇÃO DE UM PENSAMENTO MÁGICO EM MATÉRIA DE SEGURANÇA}

Nesse momento agrega-se a complexidade, visando a tratar da relação entre mídia e sua capacidade de produção de narrativas e a produção de subjetividade, que se apresenta como elemento fundamental na problemática questão da segurança pública, podendo-se apontar como o nexo central da dinâmica de aceitação da política de governo (dos corpos) e a relação estabelecida na função representativa das democracias (legitimidade).

Primeira: A segurança pública enquanto pauta política teria alguma relação com uma demanda da sociedade? Essa suposta demanda da sociedade por mais punição seria reflexo de uma realidade violenta? Tendo já respondido preliminarmente a ambos os questionamentos no capítulo anterior, chegamos à indagação: Como se dá construção da realidade da segurança pública a partir da mídia e qual relação as mídias de massa possuem com a política institucional?

Sendo esse o primeiro nível da incursão, em seguida buscaremos outra camada, em âmbito filosófico, sobre como a relação imagética característica das mídias contemporâneas, veiculadas pela mídia de massa, é traço fundamental para compreender a insensibilidade à dor e a inércia diante dos extermínios.

Na primeira camada temos como fio condutor a tese de Marília Budó, espaço em que a autora estuda a influência da mídia ${ }^{6}$ nas disputas legislativas acerca da redução da maioridade penal e em geral os posicionamentos vinculados aos atos infracionais cometidos por adolescentes.

Budó, em excelente revisão bibliográfica, aponta como chave primeira a mudança da função literária da imprensa para a função comercial. Evidentemente, o cunho comercial exigiu do gênero uma preocupação com o lucro e com a publicidade. Igualmente, saindo do gênero literário, certa objetividade (ou seja, não ficção)

\footnotetext{
6 Sobre o termo, utilizamos a definição do conceito conforme sugerido pela própria autora, a mídia como "conjunto dos meios de comunicação de massa, que realizam a mediação de diferentes tipos de mensagens para o público. Inclui-se, portanto, televisão, rádio, Internet, cinema, jornais e outros materiais impressos em grande escala" (BUDÓ, 2012, p. 238).
} 
GOVERNANDO POR MEIO DA INSENSIBILIDADE:

A SEGURANÇA PÚBLICA E GESTÃO BIOPOLÍTICA DOS CORPOS - A ADMINISTRAÇÃO DA MORTE NAS PRISÕES

Jackson Silva Leal - Alex da Rosa

passa a pautar a atuação das mídias como parâmetro de qualidade, o que podemos bem traduzir por "imparcialidade" (BUDÓ, 2012, p. 238).

A ideia de imparcialidade por si já é imensamente questionável. Mais interessante ainda, todavia, é observar as técnicas próprias ao jornalismo para criar, simular e eventualmente produzir uma aura imparcial. Nesse sentido alguns elementos fundamentais: (a) seleção das notícias, (b) seleção das fontes utilizadas e (c) linguagem aplicada (BUDÓ, 2012).

Em seus estudos a autora remonta uma ampla base que discute sobre o tema e que em geral concorda com alguns princípios básicos ao jornalismo no que se refere à seleção de notícias. Nelas, a "singularidade" do fato (a) seria característica fundamental à notícia, ou melhor, agregaria importância ao acontecimento (BUDÓ, 2012, p. 240).

O primeiro paradoxo: Se a singularidade do fato é principal característica da notícia, qual singularidade de dia após dia entulhar as páginas policiais com os mesmos crimes de furto e tráfico que abarrotam o sistema penal? O charme é tornar o evento singular, tomar dentro dessa banalidade algo que chame a atenção e o distinga, ou seja, selecionar os crimes com requintes de crueldade, que chamem a atenção, que tenham em si esse duplo singularidade-exceção.

Isso ajuda a compreender em partes o porquê de os noticiários buscarem explorar fatos e crimes sempre chocantes. É o primeiro paradoxo a divulgação cotidiana, massiva, repetitiva de crimes exemplares (violentos, impactantes) - seu valor singular - produz um universo midiático em que tal exceção é construída como realidade corrente.

A contribuição das mídias na construção do senso comum implica igualmente o se envolvimento nesse senso comum, o que adiante investigaremos como aparelho. Por ora, todavia, a contradição entre o senso comum e a realidade criminal, ou seja, segurança pública, é marcada por um distanciamento da realidade objetiva:

No caso do Brasil, essa representação social do crime não é diferente. Apesar de haverem poucos estudos sistematizados a respeito do crime na mídia, é possível visualizar naqueles existentes a discrepância entre o "retrato simbólico da criminalidade" e a ocorrência dos fatos criminosos de acordo com os registros oficiais de criminalização. O llanud realizou uma análise da programação de 27 telejornais das sete emissoras de televisão aberta do Brasil (SBT, Globo, Bandeirantes, Record, Manchete, CNT, TV Cultura), no período de 2 a 8 de agosto de 1998. Nesse período, 1.211 foram as cenas de crime nos noticiários nacionais, dos quais 714 (59\%) foram homicídios, 153 (12,6\%) lesões corporais e 141 (11,6\%) estupros. No mesmo período, as estatísticas de criminalização mostraram que apenas $1,7 \%$ dos casos registrados foram de homicídios, $27,3 \%$ de lesões corporais e $0,4 \%$ de estupros (BUDÓ, 2012, p. 256).

Entre outros elementos que auxiliam na constituição desse cenário, a (b) seleção das fontes constitui outro problema. Dentro da ideia de imparcialidade, objetividade e neutralidade, as mídias costumam privilegiar as fontes formais, ou seja, veículos oficiais estatais. Tratando-se de políticas criminais o problema fica evidente: o delegado é a principal autoridade a emitir verdade sobre o assunto em que sua corporação está envolvida (BUDÓ, 2012, p. 296), ou seja, sua versão dos fatos revestida de autoridade será bem previsível em seu favor.

A articulação é uma espécie de armadilha que visa a formar um binômio: Quem duvidaria do policial? Apenas alguém que fosse a favor da bandidagem. Isso simplifica uma série de relações sociais no que diz respeito à criminalidade e torna longo o caminho que busca sair do senso comum binário entre eles e nós.

Esses dois elementos expostos ajudam-nos a compreender como podem ser veiculadas em massa notícias em geral conservadoras no que diz respeito à política criminal. Isso porque, certa contingência, normalidade, também é característica das informações (BUDÓ, 2012, p. 248).

A construção de um universo de venda de medo constituirá o capital político e financeiro da venda (comercial) e pauta (política) da segurança pública. A normalização de crimes violentos pela exposição massiva dos veículos de comunicação sobre o tema (singularidade), aliada à construção ética distintiva entre eles e nós, já nos ajuda a compreender como a vida pode ser ao mesmo tempo um bem tutelado, mas facilmente so- 
GOVERNANDO POR MEIO DA INSENSIBILIDADE:

A SEGURANÇA PÚBLICA E GESTÃO BIOPOLÍTICA DOS CORPOS - A ADMINISTRAÇÃO DA MORTE NAS PRISÕES

Jackson Silva Leal - Alex da Rosa

breposto à propriedade (crimes contra o patrimônio), situações em que a morte do outro passa a ser tolerada e apoiada.

Ou seja, a construção de uma hegemonia discursiva e narrativa em segurança pública, fundada em dados e interesses determinados, em uma certa compreensão da realidade e desde uma estrutura subjetiva que permitem a conformação de um estado de coisas (inconstitucional?) que autoriza o deixar morrer (das prisões) ou fazer morrer (da letalidade policial). A isso Vera Malaguti Batista chamaria de adesão subjetiva à barbárie (2012).

Agora, todavia, adentramos no segundo nível da problemática. A representação cibernética própria da contemporaneidade, principalmente TVs e mídias sociais virtuais, assim como sua exposição no formato de imagem, podem servir de pistas para auxiliar na compreensão dos massacres como parte de um programa de governo.

Seria o aspecto linguístico referido anteriormente, porém tomando outros caminhos analíticos complementares ao da autora, ${ }^{7}$ mas que perfeitamente comunicam-se com os estudos sobre o interacionismo simbólico conhecido da criminologia. Para isso adentraremos brevemente na obra de Vilém Flusser, filósofo tcheco refugiado no Brasil durante o nazismo e que dedicou grande parte de sua obra à linguística, mídias e filosofia do design.

Flusser traça entre a pré-história, a história e a pós-história uma relação com a linguagem escrita e imagética. Objetivamente falando, o primeiro período seria o anterior à escrita, o segundo o descobrimento da escrita linear e o terceiro a popularização das imagens técnicas em sobreposição à escrita (2018).

Para ele, as imagens são a redução dimensional que pela abstração permitem àquele que as visualiza o processo de recodificação, ou seja, de imaginar e recompor a imagem. Isto porque elas não são espaços de pura significação inequívoca, possuem um espaço interpretativo que se refere à imaginação (FLUSSER, 2018, p. 16).

Diferentemente da escrita que obriga o leitor a uma ordem, ${ }^{8}$ a imagem tem no olhar do intérprete o significante. $O$ olhar que passa pela superfície na qual repousa a imagem pode fluir, desordenadamente, em relações reversíveis de significação.

Imagens são mediações entre o homem e mundo. O homem "existe", isto é, o mundo não lhe é acessível imediatamente. Imagens têm o propósito de representar o mundo. Mas, ao fazê-lo, entrepõe-se entre o mundo e o homem. Seu propósito não é serem mapas do mundo, mas passar a ser biombos. 0 homem, em vez de se servir das imagens em função do mundo, passa a viver em função das imagens. Não mais decifra as cenas das imagens como significados do mundo; mas o próprio mundo vai sendo vivenciado como conjunto de cenas. Tal inversão da função das imagens é idolatria. Para o idólatra - o homem que vive magicamente - a realidade reflete imagens. Podemos observar, hoje, de que forma se processa a magicização da vida: as imagens técnicas, atualmente onipresentes, ilustram a inversão da função imaginistica e remagicizam a vida (FLUSSER, 2018, p. 17).

Nesse sentido a escrita é a luta contra a idolatria. A escrita é uma forma de decompor as imagens em códigos lineares alfanuméricos, de rasgar as imagens que representam o mundo; é a diferença entre a consciência mágica e a consciência histórica. A escrita compõe conceitos que significam ideias. Descodificar textos é descobrir as imagens significadas pelos conceitos. Nas palavras do autor, a escrita "é metacódigo das imagens" (FLUSSER, 2018, p. 17).

Se em um dado momento a escrita linear veio a combater as imagens, tirar o homem da consciência mágica, hoje a imagem técnica vem a superar a escrita, o que implica uma série de consequências, como a volta da consciência mágica em detrimento da consciência histórica (FLUSSER, 2018; FLUSSER, 2007, p. 133).

Zaffaroni chama de pensamento mágico o que consegue compreender a realidade desconectada de sua objetividade, ou, como escreve o próprio Zaffaroni, "apela a uma criação da realidade através da informação,

Em outro momento já se explorou a linguagem escrita, sua relação com os processos de criminalização secundária e conexão estabelecida com as mídias de massa. "Os Crimes dos Homens Infames" (LOWENTHAL; ROSA, 2019).

8 Barthes aponta o fascismo na língua. "Mas a língua, como desempenho de toda linguagem, não é nem reacionária, nem progressista; ela é simplesmente: fascista; pois o fascismo não é impedir de dizer, é obrigar a dizer" (BARTHES, 2000, p. 14). 
GOVERNANDO POR MEIO DA INSENSIBILIDADE:

A SEGURANÇA PÚBLICA E GESTÃO BIOPOLÍTICA DOS CORPOS - A ADMINISTRAÇÃO DA MORTE NAS PRISÕES

Jackson Silva Leal - Alex da Rosa

subinformação, desinformação em convergência com preconceitos e crenças baseada em uma etiologia criminal simplista" (2013, p. 194).

Isso porque a objetividade da escrita é oposta à subjetividade imagética. A leitura de um texto, sua ordenação, o significado objetivo de seus conceitos, por mais "abstratos" que sejam, compõem uma ordenação rija, ou seja, saber ler, juntar letras e símbolos que não permitem outras significações que não as ali expressas. Já os códigos imagéticos são baseados em convenções não aprendidas conscientemente e que igualmente permitem àquele que visualiza a posição de significante (atribuir significado a cena) (FLUSSER, 2007, p. 114). $O$ significante como realidade em detrimento do significado.

Existem, todavia, importantes distinções quanto às imagens pré-históricas e as imagens técnicas. Enquanto nas primeiras as imagens tinham a função de interpretar o mundo, as atuais imagens são compostas por códigos escritos, e, se a função da escrita é a criação de conceitos, as imagens técnicas são interpretações dos conceitos e teorias referentes ao mundo (FLUSSER, 2007, p. 130).

As imagens técnicas então retomam a forma mágica de pensar o mundo (inversão do vetor de significação do significado para o significante), escapando à consciência que tais imagens são construídas em superfícies por códigos (escritos). A programação dos códigos que virão a constituir as imagens é o dispositivo constituinte da percepção da "realidade de hoje".

O caráter aparentemente não simbólico, objetivo, das imagens técnicas faz seu observador olhá-las como se fossem janelas e não imagens. O observador confia nas imagens técnicas tanto quanto confia em seus próprios olhos. Quando critica as imagens técnicas (se é que as critica), não o faz enquanto imagens, mas enquanto visões de mundo. Essa atitude do observador em face das imagens técnicas caracteriza a situação atual, em que tais imagens se preparam para eliminar textos. Algo que apresenta consequências altamente perigosas. A aparente objetividade das imagens técnicas é ilusória, pois na realidade são tão simbólicas quanto todas as imagens (FLUSSER, 2017, p. 22).

As coisas ficam interessantes: alienação sob crença de verdade. Ao consumir conteúdo midiático, o espectador participa ativamente na livre escolha daquilo que assiste, destacando-se que o meio pelo qual toma contato com o mundo, com a informação, é por meio das imagens, justamente elas que passam por janelas da realidade, escondendo a dimensão simbólica que carregam.

Isso implica a dificuldade no estabelecimento de diálogo. A informação adquirida subjetivamente no processo de visualização das imagens apresenta-se como objetiva para o intérprete, como espelho da realidade.

Nesse sentido preciso, todas as críticas são ideológicas: perda de confiança nos textos, conhecimento por empiria dos próprios sentidos a partir da visualização da realidade pelas imagens:

Isso é o que consideramos como "crise dos valores": O fato de termos retornado do mundo linear das explicações para o mundo tecno-imaginário dos "modelos". Não é o fato de as imagens eletrônicas se movimentarem, nem o de serem "audiovisuais", nem o fato de irradiarem nos raios catódicos que determina sua novidade revolucionária, mas o fato de que são "modelos", isto é, significam conceitos. Um programa de TV não é uma cena de uma circunstância, mas um "modelo", a saber, uma imagem de um conceito de uma cena. Isso é uma "crise" porque, com a superação dos textos, os antigos programas (por exemplo, a política, a filosofia, a ciência) serão anulados, sem que sejam substituídos por novos programas (FLUSSER, 2007, p. 136).

Isso põe novamente em cena o problema referente ao programa e ao aparelho. O aparelho em Flusser é passível de uma aproximação com o dispositivo em Foucault (PETRÔNIO, 2017), e é apresentado em Flusser pelo exemplo da câmera fotográfica (que inaugura as imagens técnicas). $O$ aparelho em Flusser seria aquilo que dele vemos apenas seus instrumentos, estaríamos tão inseridos no aparelho que suas bordas e limites nos escapariam, cada vez mais, em espiral ascendente (2017, p. 327).

O aparelho possui um programa, uma espécie de sistema organizado, encadeado, que escapa aos seus próprios controladores, ou até mesmo criadores de um início primitivo. O programa inicialmente criado pelo homem passa a programá-lo (FLUSSER, 2017, p. 343). Igualmente, em outras palavras, se em outras épocas o homem era a constante enquanto os instrumentos e artefatos a seu dispor eram substituídos, as máquinas passam a ser a constante, o homem é expulso da própria cultura (FLUSSER, 2007, p. 38). 
GOVERNANDO POR MEIO DA INSENSIBILIDADE:

A SEGURANÇA PÚBLICA E GESTÃO BIOPOLÍTICA DOS CORPOS - A ADMINISTRAÇÃO DA MORTE NAS PRISÕES

Jackson Silva Leal - Alex da Rosa

Podemos aqui em nosso caso concreto tomar o aparelho de Flusser na perspectiva da interação entre mídia e governo. O caráter "mágico" (pensamento mágico/criminologia midiática) das imagens tem como função tirar o homem de sua consciência história, inseri-lo numa realidade virtual a partir da informação.

A informação, principal característica da mídia, tem como função dar forma à matéria. Fabricar algo é informar. A informação, esse processo de comunicação, trata-se em suma de formação das subjetividades com finalidade (CARDOSO, 2007).

A pergunta imediata é se essa intenção do processo informativo das mídias corresponderia a um problema de superestrutura e de ideologia. Embora Budó tome um caminho gramsciano, a autora enfatiza que a interação entre mídia e governo não se dá por um determinismo biunívoco, certeiro:

(...) aqueles que consideram que a influência da mídia no discurso presidencial, por exemplo, é um efeito de agendamento, costumam encontrar forte impacto da mídia. Por outro lado, aqueles que concluíram com a ideia de que há um impacto limitado costumam definir a agenda política como a produção legislativa ou consequências administrativas concretas (BUDÓ, 2012, p. 400).

Joachim Hirsch (2014), que escreve desde uma perspectiva materialista acerca da concepção de hegemonia - permite entender que a compreensão corrente de hegemonia é superficial e que poderia remontar a uma falsa percepção de que somos governados superestruturalmente e de que cada indivíduo se constitui alegoricamente em um singelo ventríloquo - quando, de outro lado, diz respeito a como se constituem, praticam e operam as representações sociais, abarcando grupos, classes, agentes estatais, indivíduos ou mesmo até instituições.

Trata-se de disputa e articulação de forças e percepções sociais acerca da realidade. A ideia de hegemonia, portanto, se constituiria quando determinada estrutura de valores e percepções (ideologias) seja amplamente aceita, mediante sobretudo aparelhos e mecanismos de instituição. E neste ponto a mídia, os dispositivos de segurança e os aparelhos subjetivantes (ideologizantes) têm se mostrado essenciais para a construção e manutenção de uma subjetividade hegemônica e suas determinadas compreensões acerca do fenômeno criminal.

O agendamento das políticas criminais pela mídia e a sua relação com o que a criminologia chama de populismo punitivo têm possíveis caminhos interpretativos, sem cair em determinismos.

Embora beneficiem-se reciprocamente, a mídia e o governo, sobre o objeto crime, é importante frisar que ambos estão inseridos num aparelho que escapa a eles mesmos, não sendo possível pensar numa grande conspiração ou um grande programador, mas sim sistemas tão complexos e difusos que deles apenas conseguimos captar traços, ver feixes condensados dessas articulações, aqui explorados como estratégia de governo.

\section{GOVERNO ATRAVÉS DO CRIME: SUBJETIVIDADE E IDEOLOGIA NA GOVERNANÇA}

A segurança pública constitui objeto privilegiado de análise, e é possível ser articulada tanto a nível biopolítico, como demonstrado no primeiro tópico, como a nível subjetivo, como mencionado no segundo. Podemos tratar essa articulação como um programa no sentido flusseriano, ou um dispositivo de controle ou mesmo uma perspectiva de hegemonia discursiva (ou ideológica) em uma acepção mais materialista.

Ambas as dimensões podem ser articuladas se tomamos o crime como produto (produzido/construído). O crime como fato social serve tanto ao controle biopolítico da população como elemento subjetivo de coesão social veiculado massivamente pela mídia.

Se é algo comum às duas esferas, podemos compreender o quão conveniente seria uma grande oferta de crimes e o quão útil seria um grande encarceramento. Isso é pura lógica industrial de produção:

Comparada com a maioria das outras indústrias, a do controle do crime ocupa uma posição privilegiada. Não há falta de matéria-prima, a oferta de crimes parece ser inesgotável. Também não tem limite a demanda pelo serviço, bem como a disposição de pagar pelo que é entendido como segurança. E não existem os habituais problemas de poluição industrial. Pelo contrário, o papel atribuído a esta indústria é limpar, remover os elementos indesejáveis do sistema social (CHRISTIE, 1998, p. 1). 


\section{Direito Debate}

GOVERNANDO POR MEIO DA INSENSIBILIDADE:

A SEGURANÇA PÚBLICA E GESTÃO BIOPOLÍTICA DOS CORPOS - A ADMINISTRAÇÃO DA MORTE NAS PRISÕES

Jackson Silva Leal - Alex da Rosa

O tom quase jocoso de Nils Christie faz jus à lógica exposta. A questão é, em verdade, um tanto simples. Existe uma demanda da mídia por notícias, e seu produto privilegiado sendo as notícias criminais, pelos elementos já expostos anteriormente. Igualmente, existe um interesse por parte do governo em criminalizar condutas (criminalização primária) e determinados segmentos (criminalização secundária) para fins de controle social.

É uma relação circular entre mídia, mercado e governo. Os interesses da Indústria do Controle do Crime, conforme Christie já expunha, são sempre favoráveis ao excesso de oferta (1998, p. 155). Isso porque quanto mais se prender, quanto maior o volume de condutas a serem criminalizadas e segmentos da população inclusos no rol, maior será o lucro (seja político - governamental - e/ou econômico) das demais instituições envolvidas no dispositivo de segurança.

Isso fica evidente ao se observar a privatização das penitenciárias, que ao passo que aumenta o lucro do setor privado, também facilita para o Estado o modo de lidar com a problemática, aprofundando a reciprocidade da relação de ambos.

Destaca-se que apesar de ser um fenômeno crescente nos EUA e em outros países do hemisfério norte, no Brasil a privatização das prisões ainda não avança nos moldes tradicionais, mas encontra meios de se beneficiar, de se tornar mercadoria, principalmente nas questões referente à instalação de empresas privadas dentro de presídios, gozando de uma série de isenções e reduções de custo, ao mesmo tempo que gera certo capital político governamental como uma espécie de medida de cunho ressocializador (PESSOA, 2019).

Isso serve tanto ao setor público quanto ao privado. A segurança pública torna-se um emaranhado, que envolve segurança privada, privatização de presídios, venda de dispositivos de controle, cercas, grades, armas, etc. (CHRISTIE, 1998, p. 101). Por outro lado, ocorre a exposição midiática da violência, criminalidade e criação de pânico social, venda de medo e compra de segurança.

O encarceramento em massa está inserido como parte do programa de segurança pública, dessa indústria do controle do crime. Atende bem ao fim midiático e ao setor privado (como indústria da informação, do medo), assim como serve de estratégia de governo para coesão social e manutenção no poder por vias pretensamente democráticas, revestidas com o véu da legitimidade (também magicamente construída).

Michelle Alexander (2018) é minuciosa em demonstrar como, durante o século 20, uma política criminal racializada pautada pelo encarceramento em massa foi estratégia de governo, tanto para controle de segmentos da população quanto para acúmulo de capital político, o que se estende à contemporaneidade. O que pode ser encontrado também na historiografia brasileira acerca do controle populacional inaugurado quase conjuntamente com a abolição da escravatura, como medida de controle/disciplinamento e subjetivação da população negra à nova condição colocada pela sociedade moderna.

Da mesma forma que, ao longo do século 20 constituíram-se diversos inimigos e subjetividades que permitiam esse combate e disputa, legitimando essas relações conflituosas com base em determinadas percepções da realidade, produzidas principalmente por aparelhos, mecanismos e dispositivos de subjetivação e segurança (ou a conformação de determinada ideologia como representação da realidade social). É o caso do mundo bipolar e da guerra contra o comunismo no decorrer do século 20 em meio à guerra fria; e também é o caso da construção da dinâmica bélica de combate às drogas.

O que, conforme também já estudado por tantos autores, que aqui se refere ao texto de referência mais recente no Brasil, intitulado O Direito Penal da Guerra às Drogas (VALOIS, 2017) e o clássico A Face Oculta da Droga (DEL OLMO, 1990) que dá conta do movimento de criminalização das drogas, e a sua função enquanto controle social orientado a segregar e controlar determinados e específicos grupos sociais.

As etapas da criminalização, o movimento do proibicionismo foram pensados e criados para afetarem grupos específicos, mesmo não correspondendo a "anseios sociais":

Determinada a assegurar que a "nova maioria republicana" continuaria a apoiar a extraordinária expansão das atividades de aplicação da lei penal do governo federal e que o congresso continuaria a financiá-las, o governo Reagan lançou uma ofensiva midiática para justificar a guerra às drogas (ALEXANDER, 2018, p. 96-97). 


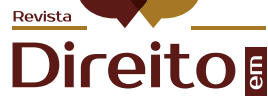 \\ Debate}

GOVERNANDO POR MEIO DA INSENSIBILIDADE:

A SEGURANÇA PÚBLICA E GESTÃO BIOPOLÍTICA DOS CORPOS - A ADMINISTRAÇÃO DA MORTE NAS PRISÕES

Jackson Silva Leal - Alex da Rosa

Acerca disso Lola Aniyar de Castro $(1976,1985)$ mostra como se deu a campanha e o processo, no qual, em um dia o uso de substâncias entorpecentes era amplamente aceito na sociedade venezuelana, e do dia para a noite tornou-se a principal pauta midiática, demonstrando a ligação das drogas com a criminalidade, com a violência, com os problemas sociais de maneira geral, e como esse processo de subjetivação (ideológica) acerca do fenômeno das drogas foi fundamental para um processo de hegemonização da compreensão acerca das drogas, sua criminalização e os grupos ligados a essas práticas.

O momento atual da realidade brasileira divide-se entre o mal, representado no traficante de drogas, e no novíssimo inimigo número um da sociedade - a corrupção - que permitiu se produzisse uma série de mudanças em nível jurídico normativo, recuo de garantias, além de toda a construção midiática (produtora de subjetividade e legitimadora de ações políticas e policiais) acerca do fenômeno da corrupção. Acerca disso não precisa maior digressão porque faz parte do presente brasileiro.

Ou seja, existe uma distinção significativa, sutil, que seria a diferenciação entre governar o crime e governar através do crime, conforme propõe Simon. Quando fala em governar por meio do crime, o autor se refere ao uso da criminalização e do encarceramento, além de todos os aparelhos e dispositivos de governo aptos, como técnica de governança, legitimando e promovendo espaços e formas de exercícios de poder (SIMON, 2007).

É o uso da imagem do crime e do criminoso sendo utilizados a todo instante para uma alteração legislativa, para retirada de garantias penais, para justificar investimento em mais prisões e polícias, até mesmo interferindo na estrutura política nacional decidindo uma eleição, ou autorizando (ainda que informalmente) uma execução sumária, a condecoração de um agente da segurança pública, ou mesmo o massacre dentro de uma unidade prisional.

A elevação do crime a esse status promove uma reorganização do Estado que em sua feição de meados do século 20 estaria ancorado em subjetividades dirigidas a uma vida de garantias e segurança voltadas para a ideia de bem-estar social, e que com a virada operada nas décadas de 70 e 80 , juntamente com o convencimento/instituição (ideológica) do colapso desse modelo societário, permite o nascimento e construção de uma estrutura social baseada e construída sobre a ideia de insegurança, de risco e da necessidade vendável de controle [de um Welfare State para um Prisonfare State, como apontam Wacquant em Punir os Pobres (2007) e Garland em Cultura do Controle (2008)].

Essa dimensão subjetiva do governo, a orientação das almas, para Foucault, é a estratégia de governo adotada pelos Estados modernos e seria diretamente uma adaptação do modelo de poder pastoral (FOUCAULT, 2008, p. 174). Uma das principais características desse novo tipo de poder seria o trabalho constante entre o coletivo e o individual, o omnes et singulatium do pastor, articulando o nível macro - referente ao biopoder, se se quiser nesses termos - e o micro, mais centrado no governo do homem na condição de indivíduo, não só acerca de seu comportamento, mas também certo nível ético de dizer a verdade sobre si.

Ou ainda, em uma acepção mais materialista acrescenta Eagleton:

Conquistar hegemonia é estabelecer liderança moral, política, intelectual na vida social, difundindo sua própria visão do mundo pelo tecido da sociedade como um todo, igualando, assim, o próprio interesse com o da sociedade em geral (EAGLETON, 2019, p. 131).

Continua ainda apontando que essa dinâmica não é corolário da sociedade capitalista, e que em nossa sociedade moderna capitalista desenvolvida, a relação consenso-coerção pende preponderantemente para o primeiro, tendo em vista justamente o desenvolvimento dos dispositivos subjetivantes/ideologizantes (mídia, escola, família ...).

Com essa nova noção, o "governo" é distinguido de seus possíveis sentidos: ao nível propriamente espiritual, a noção de impor um regime, a relação de chefia entre indivíduos, uma relação verbal ou até mesmo sexual. Fato é, contudo, que entre suas várias formas há um aspecto comum: "nunca se governa um Estado, um território, nunca se governa uma estrutura política. Quem é governado são sempre pessoas, são indivíduos, são coletividades" (FOUCAULT, 2008, p. 165) e quem governa também são pessoas à frente de partidos, de instituições, de organizações, como escreve Hirsch, "o resultado de confrontações e lutas sociais em dife- 
GOVERNANDO POR MEIO DA INSENSIBILIDADE:

A SEGURANÇA PÚBLICA E GESTÃO BIOPOLÍTICA DOS CORPOS - A ADMINISTRAÇÃO DA MORTE NAS PRISÕES

Jackson Silva Leal - Alex da Rosa

rentes planos da sociedade, cujo desenlace não pode ser pré-determinado, mas depende da força, das estratégias [...] dos atores sociais em jogo" $(2014$, p. 108). Ainda sobre o governo, conclui Foucault:

Procurei esboçar um pouco essa noção de governo, que me parece muito mais operacional do que a noção de poder, "governo" entendido, claro, não no sentido estrito e atual de instância suprema das decisões executivas e administrativas nos sistemas estatais, mas no sentido lato, e aliás antigo, de mecanismos e procedimentos destinados a conduzir os homens, a dirigir a conduta dos homens, a conduzir a conduta dos homens $(2014$, p. 13).

Tratando-se de governo, não é apenas sobre vigiar e punir, sobre disciplina e obediência, a técnica de governo da população exige uma tomada em nível individual e subjetivo do indivíduo, constituindo também a dimensão social. Isso se dá por meio da adesão à verdade, aspecto produtor do poder (FOUCAULT, 2014).

Percebemos como as coisas ficam singelamente diferentes. Concomitantemente à dimensão biopolítica, a técnica de governo contemporânea, aqui retomada pelo governo por meio do crime, envolve pensar como o indivíduo pode aderir a certas verdades, exercendo sobre si uma ascese a fim de manter-se próximo à verdade, e, claro, ao mesmo tempo afastar e rechaçar aqueles que dela se distanciam (FOUCAULT, 2014).

A mídia então aparece como espaço privilegiado de direção de consciência, articular a vontade do dirigido a coadunar-se com a do diretor, com a condição de aparente liberdade de escolha. Ou seja, o indivíduo livremente se vincula à verdade, constitui (na sua percepção) livremente sua subjetividade e é autônomo na sua formulação de juízos éticos (FOUCAULT, 2014).

Nesse sentido agrega Terry Eagleton acerca da subjetividade (ou ideologia) como quadro de representações sociais que tornadas amplamente aceitas (estabelecidas) se constituem em hegemonia discursiva, representacional e subjetiva, na qual a marca tem sido - além da negação da ideologia e de se arrogar o pálio da neutralidade - o discurso da liberdade/autonomia.

Tornamo-nos sujeitos humanos livres, autônomos, justamente submetendo-nos obedientemente ao sujeito, ou à Lei. Assim que internalizamos essa lei, que a tornamos inteiramente nossa, começamos a agir espontaneamente e inquestionavelmente. Vamos ao trabalho por nossa conta, sem necessidade de supervisão coercitiva constante, e é essa lamentável condição que reconhecemos erroneamente como liberdade (EAGLETON, 2019, p. 162).

A técnica de governo voltada para a subjetividade busca ajustar um modelo de comportamento a um sistema de valorização. A intersubjetividade seria então o processo pelo qual os indivíduos formam a si e também aos outros (FOUCAULT, 2016).

A mídia na condição de meio privilegiado de comunicação, de processos de intersubjetivação, ao pautar-se no crime como sua mercadoria igualmente privilegiada, estabelece uma relação com o governo, a nível político institucional (e o governo reciprocamente para com a mídia), e também com a população que adere subjetivamente à separação do eles e nós, ensejando o exercício do poder governamental justificado e apoiado pela reação social.

\section{CONCLUSÃO}

Assim, a modo de conclusão, pode-se destacar que o massacre de Altamira faz parte do dispositivo de segurança pública, e aparelho de controle social, não como a exceção, mas sintoma da realidade que é o sistema penal enquanto genocídio em ato. A criminalização secundária de conduta e de indivíduos estigmatizados, o esforço em tornar dicotômico o eixo ético da sociedade, a exposição imagética da atividade policial, de execuções ao vivo, tornam o massacre banal, cotidiano, parte consequente da ação policial e da transformação do extermínio em show e entretenimento.

Budó aponta na banalização das notícias relacionadas ao crime, imbricadas na singularidade corrente, a função não só informativa, mas também o caráter de entretenimento que assume (2012, p. 249).

Em outra linguagem, a relação do homem com o mundo a partir das imagens técnicas o tirou da posição de homo faber para homo ludens, aquele que apenas brinca com as coisas, está preso ao entretenimento e acredita ser livre e fazer parte de um programa (FLUSSER, 2007, p. 58). 


\section{Direito登 \\ Debate}

GOVERNANDO POR MEIO DA INSENSIBILIDADE:

A SEGURANÇA PÚBLICA E GESTÃO BIOPOLÍTICA DOS CORPOS - A ADMINISTRAÇÃO DA MORTE NAS PRISÕES

Jackson Silva Leal - Alex da Rosa

Existe uma relação circular entre as imagens e o nosso comportamento. A ideia de modelo, de opinião pública, são produto de sua própria produção - circular - entre imagem, subjetividade e realidade (FLUSSER, 2007). O uso dessas imagens, sua veiculação massiva, a articulação entre governo e mídia ao utilizarem como sua matéria prima o produto crime, é algo de benefício recíproco a ambas, fazendo parte de um programa em que elas ao mesmo tempo são também objeto.

Isso é pauta governamental. É sobre mirar na cabecinha (UOL, 2019), é sobre matar a petralhada (EXAME, 2019), é sobre legitimação das execuções policiais "sob forte emoção" (EL PAÍS, 2019). Ou seja, é sobre as narrativas, os discursos, a ideologia que é encoberta no sistema penal, e seu aparato jurídico normativo, processual, operacional.

Por isso que se fala em O governo através do crime (SIMON, 2007) que o Direito Penal e a capacidade punitiva do Estado neoliberal apresenta-se cada vez mais consolidado, e, sobretudo, pensando nas (frágeis) democracia modernas, essas narrativas, e discursos, dão voto, mantêm posições políticas, retroalimentam o eleitorado e seu anseio cada vez maior por segurança, se expandem pelo medo, atomizam a sociedade e distanciam os outros a ponto de que - pela tela (da televisão ou dos smartphones) - sua morte possa ser entretenimento.

\section{REFERÊNCIAS}

AGAMBEN, Giorgio. Estado de exceção. São Paulo: Boitempo Editorial, 2003.

AGAMBEN, Giorgio. Homo Sacer. O poder soberano e a vida nua I. Belo Horizonte: UFMG, 2007.

ALEXANDER, Michelle. A Nova Segregação: racismo e encarceramento em massa. São Paulo: Boitempo, 2018.

ANIYAR DE CASTRO, Lola. Drogas: Creación y muerte de un mito. Revista Capítulo Criminológico, Maracaibo, n. 4, p. 99-110, 1976.

ANIYAR DE CASTRO, Lola. Legitimación interna e estrategias de dominación en la campaña contra las drogas de 1984. Revista Capítulo Criminológico, Maracaibo, n. 13, p. 1-28, 1985.

BARTHES, Roland. Aula. São Paulo: Editora Cultrix, 2000.

BRASIL. Ministério Justiça e Segurança Pública. Departamento Penitenciário Nacional. Fórum Brasileiro de Segurança Pública. Levantamento Nacional de Informações Penitenciárias - Infopen Homens. Brasília, 2018. Disponível em: http://depen.gov.br/ DEPEN/noticias-1/noticias/infopen-levantamento-nacional-de-informacoes-penitenciarias-2016/relatorio_2016_22111.pdf. Acesso em: 10 dez. 2021.

BUDÓ, Marília de Nardin. Mídias e discursos do poder: a legitimação discursiva do processo de encarceramento da juventude pobre no Brasil. 2012. Tese (Doutorado) - Universidade Federal do Paraná, Curitiba, 2013.

CARDOSO, Rafael. Prefácio. In: FLUSSER, Vilém. Mundo Codificado. São Paulo: Cosac Naify, 2007.

CARVALHO, Salo de. O papel dos atores do sistema penal na era do punitivismo. Rio de Janeiro: Lúmen Juris, 2010.

CHIES, Luiz Antônio Bogo et al. Mortes sob Custodia Prisional no Brasil: prisões que matam; mortes que pouco importam. Revista de Ciências Sociales, Montevideo: Universidad de la República, v. 32, n. 45, p. 67-90, 2019.

CHRISTIE, Nils. La industria del control del delito: la nueva forma del holocausto? Buenos Aires: del Puerto, 1993.

CHRISTIE, Nils. Indústria do controle do crime. Rio de Janeiro: Forense, 1998.

CHRISTIE, Nils. Uma razoável quantidade de crime. Rio de Janeiro: Revan, 2011.

CHRISTIE, Nils. Limites à dor. Belo Horizonte: D'Plácido, 2016.

DEL OLMO, Rosa. A face oculta da droga. Rio de Janeiro: Revan, 1990.

D'URSO, Flávia. A crise da representação política do Estado. São Paulo: Manole, 2016.

EAGLETON, Terry. Ideologia: uma introdução. São Paulo: Boitempo, 2019.

EL PAIS. Plano Moro afrouxa regras para policiais que matam e sugere medidas que já foram barradas: Pacote anticrime de ministro é a primeira medida efetiva apresentada pela gestão Bolsonaro. Disponível em: https://brasil.elpais.com/brasil/2019/02/04/politica/1549311947_740805.html. Acesso em: ago. 2019.

EXAME. Vamos fuzilar a petralhada. Disponível em: https://exame.abril.com.br/brasil/vamos-fuzilar-a-petralhada-diz-bolsonaro-em-campanha-no-acre/. Acesso em: setembro 2019.

FLUSSER, Vilém. Mundo codificado. São Paulo: Cosac Naify, 2007.

FLUSSER, Vilém. O último juízo: gerações II. São Paulo: É Realizações Editora, 2017. 


\section{Direito自 Debate}

GOVERNANDO POR MEIO DA INSENSIBILIDADE:

A SEGURANÇA PÚBLICA E GESTÃO BIOPOLÍTICA DOS CORPOS - A ADMINISTRAÇÃO DA MORTE NAS PRISÕES

Jackson Silva Leal - Alex da Rosa

FLUSSER, Vilem. A Filosofia da Caixa Preta. São Paulo: É Realizações Editora, 2018.

FOUCAULT, Michel. História da sexualidade I. São Paulo: Editora Graal, 2006.

FOUCAULT, Michel. Segurança, território e população. São Paulo: Editora Martins Fontes, 2008.

FOUCAULT, Michel. Governo dos vivos. São Paulo: Editora Martins Fontes, 2014.

FOUCAULT, Michel. Subjetividade e Verdade. São Paulo: Editora Martins Fontes, 2016.

GARLAND, David. A cultura do controle: crime e ordem social na sociedade contemporânea. Rio de Janeiro: Revan, 2008.

HIRSCH, Joachim. Teoria materialista do Estado. Rio de Janeiro: Revan, 2014.

LEMOS, Clécio. Foucault e o Abolocionismo penal. 2018. 208 f. Tese (Doutorado) - Curso de Pós Graduação em Direito, PUC-RJ, Rio de Janeiro, 2018.

LOWENTHAL, Fritz; ROSA, Alex. Sociedade Punitiva: a vida dos homens infames. In: WOLKMER, Carlos; VIEIRA, Reginaldo (org.). Direitos Humanos e Sociedade. Santa Cruz do Sul: Essere Nel Mundo, 2018, v. 1. p. 141-155.

MALAGUTI BATISTA, Vera. Adesão subjetiva à barbárie. In: BATISTA, Vera Malaguti (org). Loic Wacquant e a questão penal no capitalismo neoliberal. Rio de Janeiro: Revan, 2012. p. 307-318.

PESSOA, Sara Araujo. Estrutura social e trabalho prisional: sobre as funções (latentes) do trabalho prisional - um estudo de caso na penitenciária Sul de Criciúma. Dissertação (Mestrado) - Programa de Pos-Graduação em Direito, Criciúma/SC, 2019.

PETRÔNIO, Rodrigo. Prefácio. In: FLUSSER, Vilem. O último juízo: gerações II. São Paulo: É Realizações Editora, 2017.

PIMENTA, Victor Martins. Por trás das grades: o encarceramento em massa no Brasil. Rio de Janeiro: Revan, 2018.

SIMON, Jonathan. Governing Through Crime: How the War on Crime Transformed American Democracy and Created a Culture of Fear. New York: Oxford Press, 2007.

UOL. A polícia vai mirar na cabecinha e fogo. Disponível em: https://noticias.uol.com.br/ultimas-noticias/agencia-estado/2018/11/01/a-policia-vai-mirar-na-cabecinha-e-fogo-afirma-wilson-witzel.htm. Acesso em: fev. 2019.

VALOIS, Luís Carlos. O direito penal da guerra às drogas. Belo Horizonte: D'Placido, 2017.

WACQUANT, Loic. Punir os pobres: a nova gestão da miséria nos Estado Unidos - a onda punitiva. Rio de Janeiro: Revan, 2007. ZACCONE, Orlando. Indignos de vida: a forma jurídica da política de extermínio de inimigos na cidade do Rio de Janeiro. Rio de Janeiro: Revan, 2015.

ZAFFARONI, Eugenio Raul. A questão criminal. Rio de Janeiro: Revan, 2013.

ZEYNEP, Gambetti. Agir em tempos sombrios. Porto Alegre: Criação Humana, 2019. 